\title{
molecules
}

ISSN 1420-3049

www.mdpi.com/journal/molecules

Article

\section{Structure of Supramolecular Assemblies Formed by $\alpha, \delta$-Tetramethylcucurbit[6]uril and 4-Nitrophenol}

\author{
Li-Mei Zheng ${ }^{1}$, Yun-Qian Zhang ${ }^{2,3}$, Jin-Ping Zeng ${ }^{2,3}$, Yan Qiu ${ }^{2,3}$, Da-Hai Yu ${ }^{2,3}$, \\ Sai-Feng Xue ${ }^{2,3}$, Qian-Jiang Zhu ${ }^{2,3}$ and Zhu Tao ${ }^{2,3, *}$
}

1 School of Chemistry and Chemical Engineering, Henan University of Technology, Zhengzhou 450001, People's Republic of China

2 Key Laboratory of Macrocyclic and Supramolecular Chemistry of Guizhou Province, Guizhou University, Guiyang 550025, People's Republic of China

3 Institute of Applied Chemistry, Guizhou University, Guiyang 550025, People's Republic of China

* Author to whom correspondence should be addressed; e-mail: zhenglimei0423@163.com; Tel. (+86) $37167756718 ; \operatorname{Fax}(+86) 37167756718$.

Received: 8 October 2008; in revised form: 2 November 2008 / Accepted: 5 November 2008 / Published: 12 November 2008

\begin{abstract}
A host-guest assembly, $\left[\left(\mathrm{C}_{40} \mathrm{H}_{44} \mathrm{~N}_{24} \mathrm{O}_{12}\right) \cdot\left(\mathrm{C}_{6} \mathrm{H}_{5} \mathrm{NO}_{3}\right)_{8} \cdot 13\left(\mathrm{H}_{2} \mathrm{O}\right)\right](\mathbf{1})$, based on a partial substituted cucurbituril, $\alpha, \delta$-tetramethylcucurbit[6]uril (TMeQ[6]), and 4-nitrophenol was synthesized and structurally characterized by single-crystal X-ray diffraction. A combination of hydrogen-bonding between the latticed water molecule and the hydroxyl group of 4-nitrophenol, the hydroxyl group of 4-nitrophenol and the carbonyl groups lining the portals in additon, the $\mathrm{C}-\mathrm{H} \cdots \pi$ interactions between the 4-nitrophenol molecules could be the driving forces of formation such an exclusion host-guest assembly.
\end{abstract}

Keywords: $\quad \alpha, \delta$-Tetramethylcucurbit[6]uril $\quad(\mathrm{TMeQ}[6]) ; \quad 4-N i t r o p h e n o l ; \quad$ Exclusion host-guest assembly; Driving forces. 


\section{Introduction}

The chemistry of cucurbit[n] urils $(\mathrm{Q}[\mathrm{n}] \mathrm{s})$ has been studied extensively [1] since the first member of the family, cucurbituril, was structurally characterized by Mock and coworkers in 1981 [2]. The cucurbit[n]urils include cucurbituril (Q[6]) and its homologues, cucurbit [n = 5, 7, 8 and 10]urils (Q[5], $\mathrm{Q}[7], \mathrm{Q}[8]$ and $\mathrm{Q}[10])$ [3-5], and a series of fully or partially substituted derivatives and analogues [6-12]. The members of the cucurbit[n]uril family have common characteristic features, such as a hydrophobic cavity and polar carbonyl groups surrounding the opening portals. In addition, their varying cavity and portal sizes lead to the formation of inclusion or exclusion complexes with different organic or inorganic species. They also present remarkable molecular recognition properties and act as building blocks for supramolecular chemistry [5,13-18]. Up to now, the supramolecular assemblies of metal or cluster aqua complexes involving the Q[n]s have been mainly limited in those with Q[6] or Q[8]. After Mock and Kim's research [19,20], Fedin and coworkers have done major work in this area and their results were summarized in reviews [21,22]. They found that alkali and alkaline earth metal ions are coordinated directly with carbonyl oxygen atoms of Q[6], but transition metal ions prefer to form hydrogen bonds between the polar $\mathrm{C}=\mathrm{O}$ groups of $\mathrm{Q}[6]$.

We previously reported the controlled synthesis of $\alpha, \delta$-tetramethylcucurbit[6]uril (TMeQ[6]) and the preparation of some supramolecular assemblies of metal aqua complexes and host-guest inclusion complexes involving this substituted Q[n]s (Figure 1)[11]. In this work, we report the crystal structures of an exclusion supramolecular assembly of TMeQ[6] with 4-nitrophenol

Figure 1. Structure of TMeQ[6].

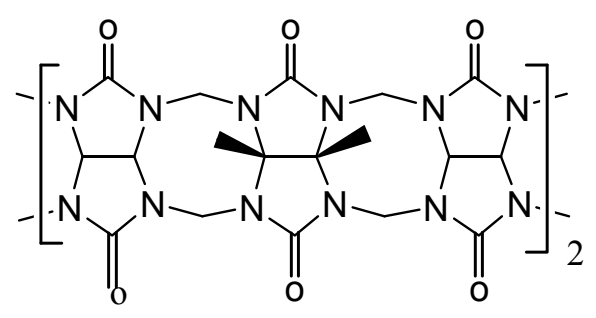

\section{Results and Discussion}

The X-ray structure of TMeQ[6] shows that it is a macrocyclic cavity with two identical portals surrounded by carbonyl groups. Unlike the normal cucurbit[n=5-10]urils, the $\alpha, \delta$-substituted Q[6] macrocycle is not circular, but ellipsoid. Its structure is easy to deform and includes molecules which could not be included by the normal cucurbit[6]uril [23].

In the crystal structure of an exclusion host-guest assembly of TMeQ[6] with 4-nitrophenol, the phenyl moiety of 4-nitrophenol was not included in the TMeQ[6] cavity due to some unfavorable interactions between the carbonyl oxygens of the TMeQ[6] and the 4-nitrophenol nitro group. However, an excluding interaction between the carbonyl oxygens of the TMeQ[6] and hydroxyl group of 4-nitrophenol was observed in compound 1. There were two different styles of TMeQ[6] molecules, one included four water molecules (marked Q1), while the other included nothing in the cavity (marked Q2). The structural characteristics of the two styles of TMeQ[6] were obviously different. As 
shown in Figure 2a, the Q1 is ellipsoid, and the distance between the O3 and O6 portal oxygens is about $7.676 \AA$, while the distance between the portal oxygens O2 and O4 is only $5.289 \AA$. The distance between the cavity carbons $\mathrm{C} 14$ and $\mathrm{C} 15$ is about $10.982 \AA$, while the distance between the cavity carbons C3 and C8 is about $8.777 \AA$. The distance between H20A and H19B is about $14.768 \AA$. For the Q2 (Figure $2 \mathrm{~b}$ ), the corresponding distance between the portal oxygens $\mathrm{O} 9$ and $\mathrm{O} 12$ is about 6.526 $\AA$, the corresponding distance between the portal oxygens $\mathrm{O} 8$ and $\mathrm{O} 10$ is $6.529 \AA$. The distance between the cavity carbons $\mathrm{C} 34$ and $\mathrm{C} 35$ is about $9.955 \AA$, while the distance between the cavity carbons $\mathrm{C} 23$ and $\mathrm{C} 28$ is about $9.751 \AA$. The distance between H40A and H39B is about $13.701 \AA$.

Figure 2. Two different styles of TMeQ[6] molecules (a) Q1 and (b) Q2.

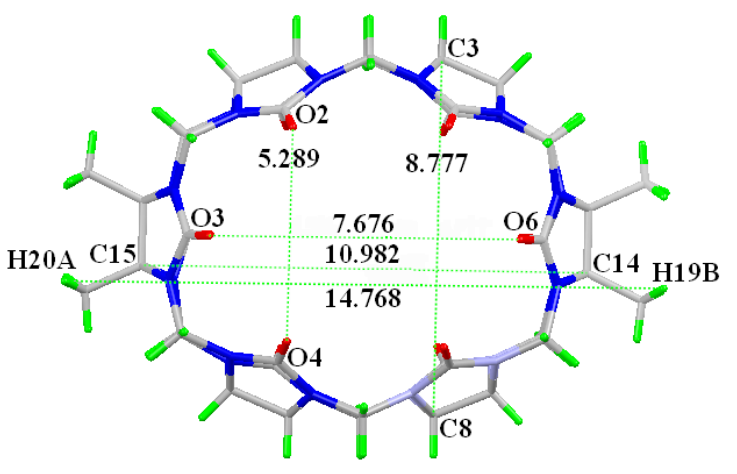

$2 \mathrm{a}$

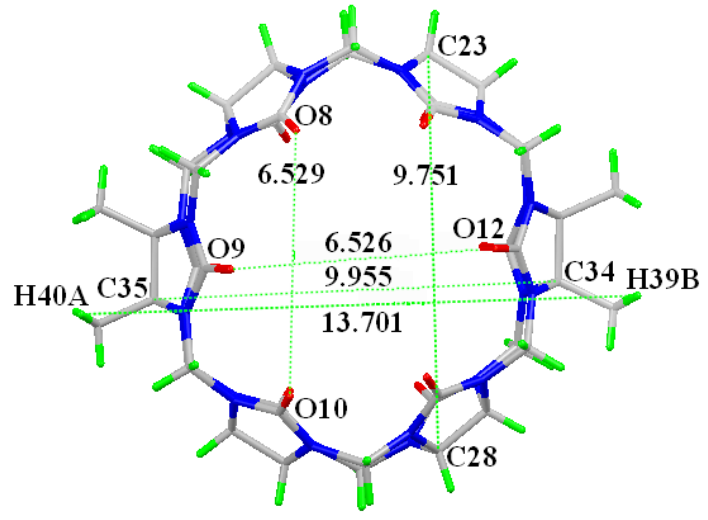

$2 b$

As mentioned above, TMeQ [6] is easy to be deformed, and the different deformation of the two types of TMeQ [6] in the title compound could be caused by the different interactions with included water molecules, excluded 4-nitrophenol molecules or latticed water molecules. For the Q1, four water molecules $\mathrm{O} 12 \mathrm{~W}, \mathrm{O} 12 \mathrm{~W}^{\mathrm{i}}, \mathrm{O} 13 \mathrm{~W}$ and $\mathrm{O}_{13} \mathrm{~W}^{\mathrm{i}}$ form a diamond plane in the cavity of the TMeQ[6] (symmetry codes: (i) 1-x, 1-y, -z). Both portals of Q1 are covered a "net" formed through the hydrogen-bonding of carbonyl oxygens and the latticed water molecules, in addition, the

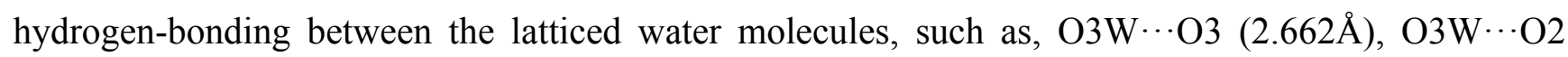

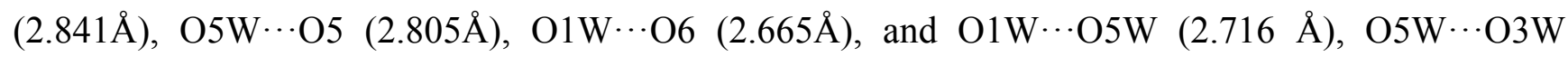
$(2.715 \AA)$. Thus, a molecular encapsulate of TMeQ[6] with four included water molecules and the two covered nets is formed. Both portals of Q2 are also covered a "net" formed through the hydrogen-bonding of carbonyl oxygens and the latticed water molecules, in addition, the

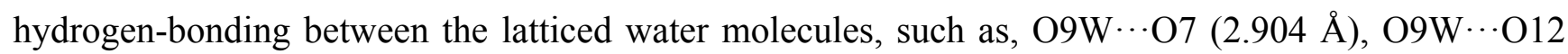

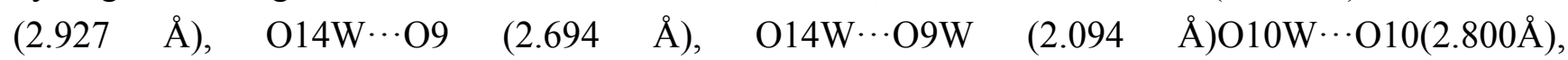
O10W $\cdots \mathrm{O} 11(2.817 \AA)$ and $\mathrm{O} 10 \mathrm{~W} \cdots \mathrm{O} 9 \mathrm{~W}(2.778 \AA)$. Moreover, a 4-nitrophenol interacts with Q2 through the hydrogen-bonding of $\mathrm{O} 16 \cdots \mathrm{O} 8(2.733 \AA)$. In this case, one can only see a molecular encapsulate shell. 
Figure 3. The molecular encapsulate based on the Q1 (a), and the the molecular encapsulate shell based on the Q2 (b).

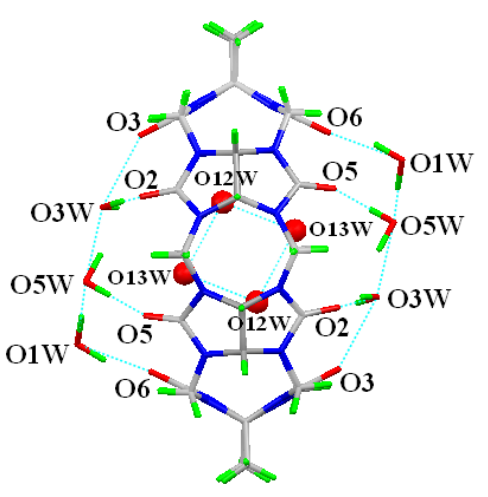

$3 \mathrm{a}$

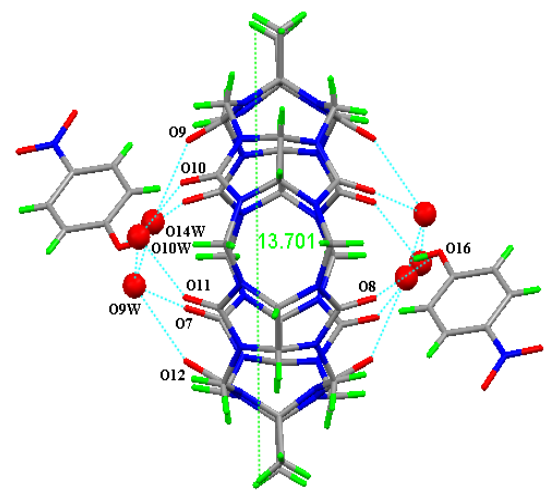

$3 \mathrm{~b}$

In the crystal structure of compound 1, the guest 4-nitrophenol was not included in the cavity of the host TMeQ[6]. However, every eight 4-nitrophenol molecules assembled through not only the hydrogen bonding of the latticed water molecules, but also the $\mathrm{C}-\mathrm{H} \cdots \pi$ interaction, and there are two different 4-nitrophenol assemblies. In the first 4-nitrophenol assembly (A1), a chair shape cyclic cluster consists of six water molecules $\mathrm{O} 2 \mathrm{~W}, \mathrm{O} 2 \mathrm{~W}^{\mathrm{ii}}, \mathrm{O} 4 \mathrm{~W}, \mathrm{O} 4 \mathrm{~W}^{\mathrm{ii}}$, O6W O6W $\mathrm{W}^{\mathrm{ii}}$ (symmetry codes: (ii)

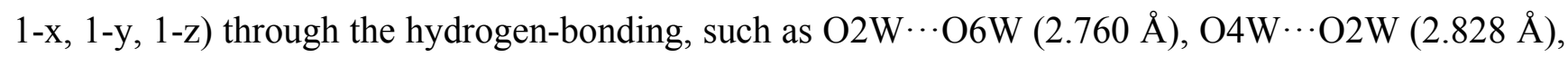
O6W $\cdots$ O4W $(2.960 \AA)$, every water molecule of this six member ring connects a 4-nitrophenol molecule, except the water molecule O6W, which connects two 4-nitrophenol molecules through the hydrogen-bonding, such as $\mathrm{O} 22 \cdots \mathrm{O} 4 \mathrm{~W}(2.650 \AA), \mathrm{O} 28 \cdots \mathrm{O} 2 \mathrm{~W}(2.708 \AA)$, O6W $\cdots \mathrm{O} 25(3.011 \AA)$,

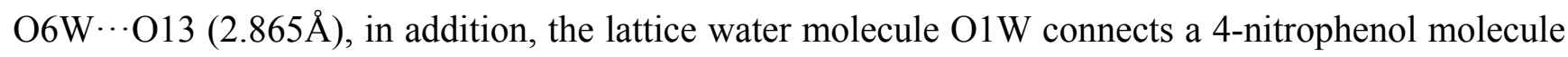
and other water molecule $\mathrm{O} 2 \mathrm{~W}$. Thus, the eight 4-nitrophenol molecules are assembled together in a tail to tail manner (Figure 4a). However, in the second 4-nitrophenol assembly (A2), six lattice water molecules $\mathrm{O} 7 \mathrm{~W}, \mathrm{O} 7 \mathrm{~W}^{\mathrm{iii}}$, O8W, O8W $\mathrm{W}^{\mathrm{iii}}$, O11W O11W $\mathrm{W}^{\mathrm{iii}}$ (symmetry codes: (iii) 1-x, 1-y, 1-z) connect four 4-nitrophenol molecules of the second assembly through hydrogen bonding, such as

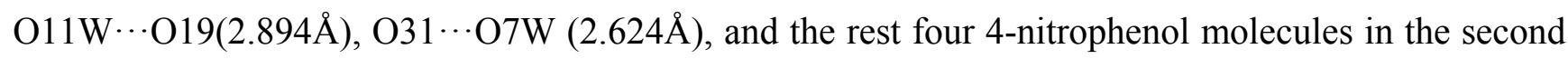
assembly seem to be independent (Figure $4 b$ ).

Figure 4. Two different 4-nitrophenol assemblies(4a) A1 and (4b) A2.

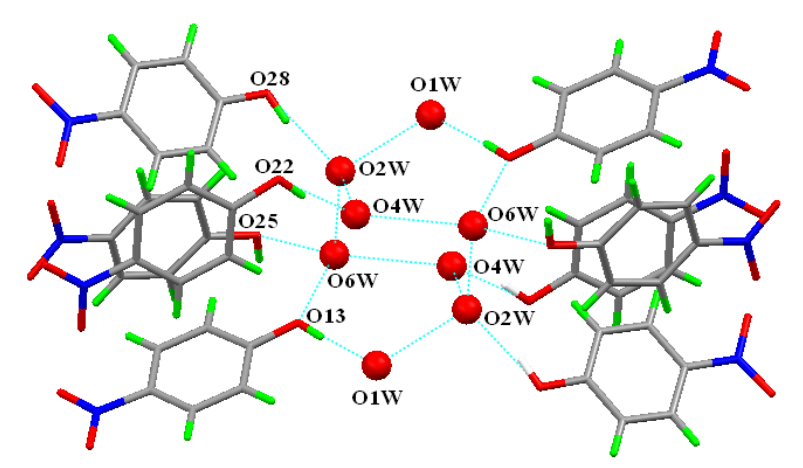

$4 \mathrm{a}$

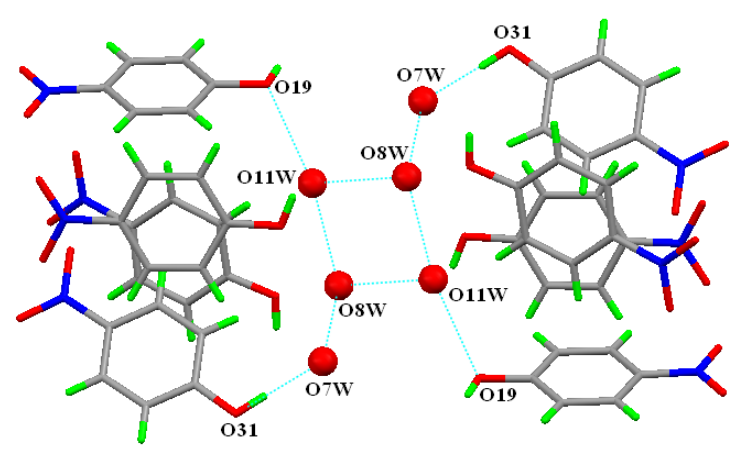

$4 \mathrm{~b}$ 
In both 4-nitrophenol assemblies, we did not observed the $\pi$ - $\pi$ stacking which normally occurred in the crystal structure of aromatic compounds, but the $\mathrm{C}-\mathrm{H} \cdots \pi$ structure [24-26]. In the structure, there are eight $\mathrm{C}-\mathrm{H} \cdots \pi$ structures and each of them is symmetric (Table 1, Figure 5).

Table 1. The C-H... $\backslash \mathrm{p}$ interactions $(\AA, \circ)$.

\begin{tabular}{ccccccc}
\hline $\mathrm{C}-\mathrm{H} \ldots \pi$ & $\mathrm{C}-\mathrm{H}(\AA)$ & $\mathrm{H} \ldots \mathrm{Cg}(\AA)$ & $\mathrm{C} \ldots \mathrm{Cg}(\AA)$ & $\mathrm{C}-\mathrm{H} \ldots \mathrm{Cg}(\AA)$ & aromatic ring & symmetry codes \\
\hline $\mathrm{C} 46-\mathrm{H} 46 \ldots \mathrm{Cg}(1)$ & 0.93 & 2.862 & $3.647(3)$ & 120.27 & $\mathrm{C} 65-\mathrm{C} 70$ & \\
$\mathrm{C} 67-\mathrm{H} 67 \ldots \mathrm{Cg}(2)$ & 0.93 & 2.802 & $3.629(3)$ & 148.80 & $\mathrm{C} 71-76$ & $\mathrm{x}, \mathrm{y}, 1+\mathrm{z}$ \\
$\mathrm{C} 75-\mathrm{H} 75 \ldots \mathrm{Cg}(3)$ & 0.93 & 2.620 & $3.316(4)$ & 132.14 & $\mathrm{C} 59-\mathrm{C} 64$ & \\
$\mathrm{C} 63-\mathrm{H} 63 \ldots \mathrm{Cg}(4)$ & 0.93 & 2.733 & $3.533(3)$ & 144.68 & $\mathrm{C} 41-\mathrm{C} 46$ & $\mathrm{x}, \mathrm{y},-1-\mathrm{z}$ \\
$\mathrm{C} 57-\mathrm{H} 87 \ldots \mathrm{Cg}(5)$ & 0.93 & 3.693 & $4.332(4)$ & 128.03 & $\mathrm{C} 83-\mathrm{C} 88$ & \\
$\mathrm{C} 87-\mathrm{H} 87 \ldots \mathrm{Cg}(6)$ & 0.93 & 2.985 & $3.601(3)$ & 125.10 & $\mathrm{C} 77-\mathrm{C} 82$ & \\
$\mathrm{C} 79-\mathrm{H} 79 \ldots \mathrm{Cg}(7)$ & 0.93 & 2.942 & $3.499(3)$ & 119.81 & $\mathrm{C} 47-\mathrm{C} 52$ & \\
$\mathrm{C} 49-\mathrm{H} 49 \ldots \mathrm{Cg}(8)$ & 0.93 & 2.645 & $3.696(3)$ & 152.80 & $\mathrm{C} 53-\mathrm{C} 58$ & $1-\mathrm{x}, 1-\mathrm{y}, 1-\mathrm{z}$ \\
\hline
\end{tabular}

It is conceivable that the $\mathrm{C}-\mathrm{H} \cdots \pi$ interaction could be a driving force of formation of the 4-nitrophenol assembly although no hydrogen-bonding exist between the latticed water molecules and the 4-nitrophenol molecules in the A2. The $\mathrm{C}-\mathrm{H}^{\cdots} \cdots \pi$ interaction occurring in the $\mathbf{A} 1$ could further strengthen the 4-nitrophenol assembly in this case.

Figure 5. The $\mathrm{C}-\mathrm{H} \cdots \pi$ structures in the two different 4-nitrophenol assemblies.

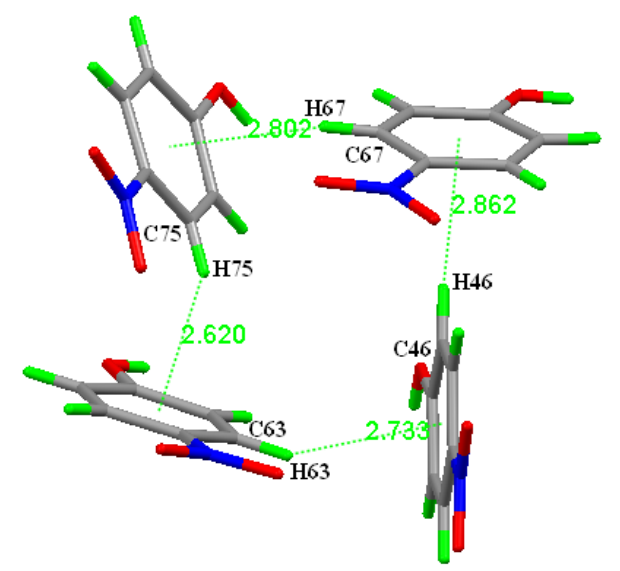

$5 \mathrm{a}$

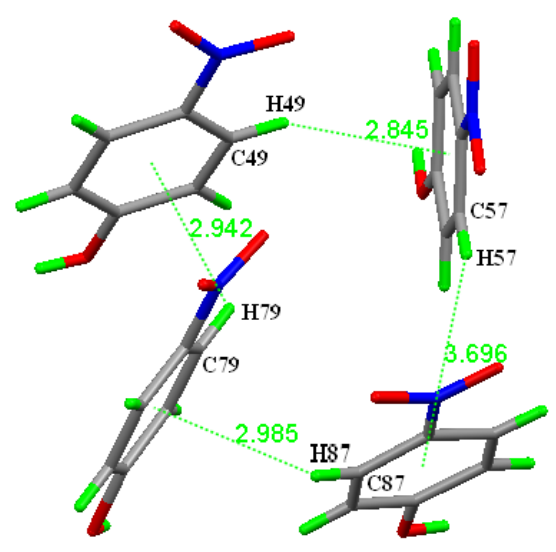

$5 b$

Here we presented an assembly based on $\mathrm{TMeQ}[6]$ and 4-nitrophenol, where several main interactions could be the diving forces of the formation of this exclusion host-guest assembly. First, the hydrogen-bonding of carbonyl oxygens of TMeQ[6] and the latticed water molecules, in addition, the hydrogen-bonding between the latticed water molecules. Second, the hydrogen bonding of the hydroxyl group of 4-nitrophenol and the latticed water molecules. Third, the $\mathrm{C}-\mathrm{H} \cdots \pi$ interactions between 4-nitrophenol molecules. Thus, in the assembly of the title compound, the two different $\mathrm{TMeQ}[6](\mathrm{Q} 1$ and Q2) array alternatively, and the assemblies (A1 and A2) scatter in the spaces of the 
lattice of TMeQ[6] (refer to Figure 6).

Figure 6. The assembly based on TMeQ[6] and 4-nitrophenol in the compound $\mathbf{1 .}$

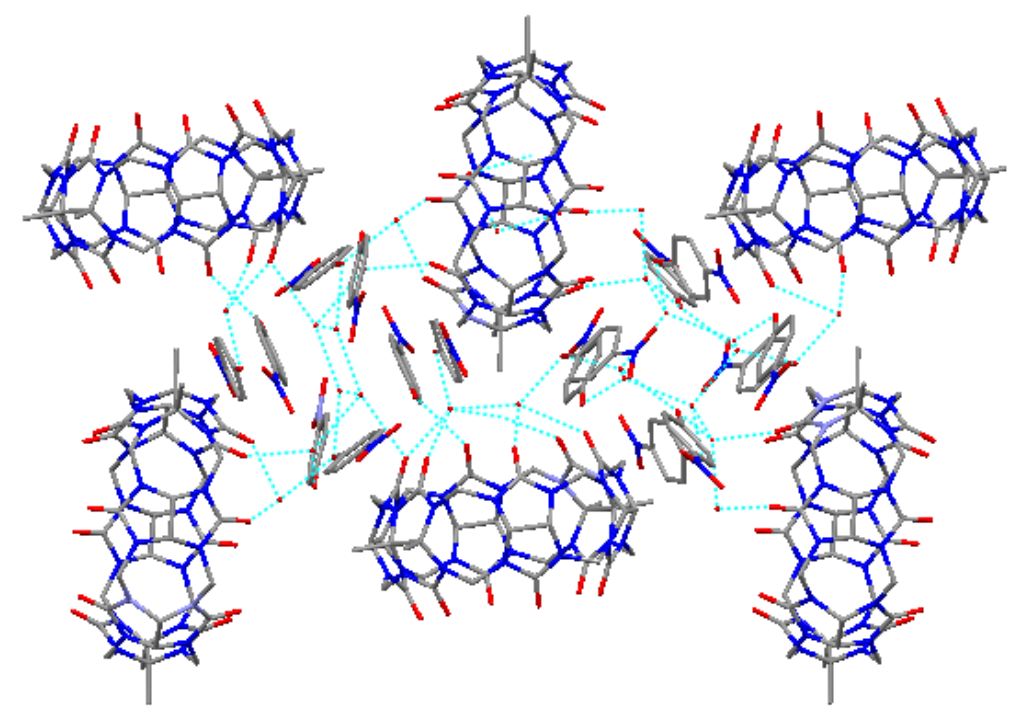

\section{Experimental}

\section{General}

4-Nitrophenol was of reagent grade and used without further purification. The TMeQ[6] was prepared by procedures reported previously [11]. Elemental analysis was carried out on an EURO EA-3000 element analyzer.

Preparation of (TMeQ[6]-4nitrophenol) $\cdot 13 \mathrm{H}_{2} \mathrm{O}(\mathbf{1})$

Single crystals of the $\mathrm{Me}_{4} \mathrm{Q}[6]$ adduct with 4-nitrophenol were obtained by dissolving $\mathrm{Me}_{4} \mathrm{Q}[6]$ $(0.50 \mathrm{~g}, 0.47 \mathrm{mmol})$ in a solution of 4-nitrophenol $(0.53 \mathrm{~g}, 3.81 \mathrm{mmol})$ in water $(10 \mathrm{~mL})$. The final solution was mixed thoroughly and allowed to stand at room temperature; crystals formed after several days, and were collected.

\section{X-ray Crystallography}

The crystal data of the substituted cucurbiturils coordinated with metal ions were collected on a SMART ApexII CCD diffractometer with graphite monochromated Mo Ka radiation $(\lambda=0.71073 \AA)$ in the $\omega-\varphi$ scan mode. Lorentz polarization and absorption corrections were applied. Structural solution and full matrix least-squares refinement based on $F^{2}$ were performed with the SHELXS-97 and SHELXL-97 program package[27], respectively. All the non-hydrogen atoms were refined anisotropically. Analytical expressions of neutral-atom scattering factors were employed, and anomalous dispersion corrections were incorporated. The crystallographic data, data collection conditions, and refinement parameters for the compound $\mathbf{1}$ are listed in Table 2. 
Table 2. Crystallographic data for complex 1.

\begin{tabular}{cccc}
\hline Empirical formula & $\mathrm{C}_{88} \mathrm{H}_{110} \mathrm{~N}_{32} \mathrm{O}_{49}$ & Dcalcd, $\mathrm{g} \mathrm{cm}{ }^{-3}$ & 1.491 \\
Formula weight & 2400.08 & $\mathrm{~T}, \mathrm{~K}$ & 223 \\
Crystal system & Monoclinic & $\mu, \mathrm{mm}-1$ & 0.123 \\
Space group & $\mathrm{P}-1$ & unique reflns & 18398 \\
$\mathrm{a}, \AA$ & $17.758(6)$ & obsd reflns & 11799 \\
$\mathrm{~b}, \AA$ & $17.908(6)$ & params & 1533 \\
$\mathrm{c}, \AA$ & $18.941(7)$ & $\mathrm{Rint}$ & 0.0430 \\
$\alpha, \mathrm{deg}$ & $88.290(5)$ & $\mathrm{R}[\mathrm{I}>2 \sigma(\mathrm{I})]^{*}$ & 0.0828 \\
$\beta$, deg & $83.072(5)$ & $\mathrm{wR}[\mathrm{I}>2 \sigma(\mathrm{I})] \#$ & 0.2562 \\
$\gamma, \mathrm{deg}$ & $63.602(5)$ & $\mathrm{R}(\mathrm{all}$ data $)$ & 0.1228 \\
$\mathrm{~V}, \AA^{3}$ & 5346 & $\mathrm{WR}(\mathrm{all}$ data $)$ & 0.2786 \\
$\mathrm{Z}$ & 2 & $\mathrm{GOF}$ on $\mathrm{F} 2$ & 1.052 \\
\hline \multicolumn{4}{c}{ Conventional $R$ on $\mathrm{F}_{h k l}: \Sigma|| F_{\mathrm{O}}|-| F \mathrm{c} \| / \Sigma\left|F_{\mathrm{o}}\right| \cdot$} \\
\end{tabular}

Crystallographic data (excluding structure factors) for the structure reported in this paper have been deposited with the Cambridge Crystallographic Data Centre as Deposition No. CCDC 659590. Copies of the data can be obtained free of charge on application to CCDC, 12 Union Road, Cambridge CB2 1EZ, UK (Fax: + 44-1223/336-033; E-mail: deposit@ccdc.cam.ac.uk).

\section{Acknowledgements}

This work was supported by the National Natural Science Foundation of China (NSFC; No. 20662003), the International Collaborative Project of the Ministry of Science and Technology (ICPMST; No. 2003DF000030) and the Foundation of the Governor of Guizhou Province.

\section{Supporting Information Available}

Experimental details of X-ray crystal structure determination, tables of X-ray data collection/refinement parameters, atomic position parameters, and anisotropic displacement parameters for 1 .

\section{References}

1. Lagona, J.; Mukhopadhyay, P.; Chakrabarti, S.; Isaacs, L. The Cucurbit[n]uril Family. Angew. Chem. Int. Ed. 2005, 44, 4844.

2. Freeman, W. A.; Mock,W. L.; Shih, N. Y. Cucurbituril. J. Am. Chem. Soc. 1981, 103, 7367-7368.

3. Day, A. I.; Arnold, A. P.; Blanch, R. J. Method for Synthesis of Cucurbiturils. [WO Patent 0068232, 2000]. 
4. Kim, J.; Jung, I. S.; Kim, S. Y.; Lee, E.; Kang, J. K.; Sakamoto, S.; Yamaguchi, K.; Kim, K. New Cucurbit Homologues: Syntheses, Isolation, Characterization, and X-ray Crystal structures of Cucurbit[n]uril (n= 5, 7, and 8). J. Am. Chem. Soc. 2000, 122, 540-541.

5. Day, A. I.; Blanck, R. J; Amold, A. P.; Lorenzo, S.; Lewis, G. R.; Dance, I. A cucurbituril-based gyroscane: a new supramolecular form. Angew. Chem. Int. Ed. 2002, 41, 275-277.

6. Zhao, J.; Kim, H. J.; Oh, J.; Kim, S. Y.; Lee, J.; Sakamoto, W. S.; Yamaguchi, K.; Kim, K. Cucurbit[n] uril Derivatives Soluble in Water and Organic Solvents. Angew. Chem. Int. Ed. 2001, 40, 4233-4235.

7. Sasmal, S.; Sinha, M. K.; Keinan, E. Facile Purification of Rare Cucurbiturils by Affinity Chromatography. Org. Lett. 2004, 6, 1225-1228.

8. Jon, S. Y.; Selvapalam, N.; Oh, D. H.; Kang, J. K.; Kim, S. Y.; Jeon, Y. J.; Lee, J. W.; Kim, K. Facile Synthesis of Cucurbit[n]uril Derivatives via Direct Functionalization: Expanding Utilization of Cucurbit[n]uril. J. Am. Chem. Soc. 2003, 125, 10186-10187.

9. Isobe, H.; Sato, S.; Nakamura, E. Synthesis of disubstituted cucurbit[n]uril and its rotaxane derivative. Org. Lett. 2002, 4, 1287-1289.

10. Day, A. I.; Arnold, A. P.; Blanch, R. J. A method for synthesizing partially substituted cucurbit[n]uril. Molecules 2003, 8, 74-84.

11. Zhao, Y.-J.; Xue, S.-F.; Zhu, Q.-J.; Tao,Z.; Zhang, J.-X.; Wei, Z.-B.; Long, L.-S.; Hu, M.-L.; Xiao, H.-P.; Day, A. I. Synthesis of a symmetrical tetrasubstituted cucurbit[6]uril and its host-guest compound with 2, 2'-bipyridine. Chin. Sci. Bull. 2004, 49, 1111-1116.

12. Lagona, J.; Fettinger, J. C.; Isaacs, L. Cucurbit[n]uril Analogues. Org. Lett. 2003, 5, 3745-3747.

13. Fu, H.-Y.; Xue, S.- F.; Zhu, Q.-J.; Tao, Z.; Zhang, J.-X.; Day, A. I. Investigation of host - guest compounds of cucubit $[\mathrm{n}=5-8]$ uril with some ortho pyridiniumammonium Ions. J. Inc. Phenom. Macro. Chem. 2005, 52, 101-107.

14. Kim, K.; Kim, D.; Lee, J. W.; Ko, Y. H.; Kim, K. Growth of poly(pseudorotaxane) on gold using host - stabilized charge - transfer interaction. Chem. Commun. 2004, 848-849.

15. Pattabiraman, M.; Natarajan, A.; Kaliappan, R. Template directed photodimerization of trans-1,2-bis(n-pyridyl) ethylenes and stilbazoles in water. Chem. Commun. 2005, 4542-4544.

16. Buschmann,H. J.; Mutihac, L.; Mutihac, R. C.; Schollmeyer, E. Complexation behavior of cucurbit[6]uril with short polypeptides. Thermochim. Acta 2005, 430, 79-82.

17. Lee, H. K.; Park, K. M.; Jeon, Y. J.; Kim, D.; Oh, D. H.; Kim, H. S.; Park, C. K.; Kim, K. Vesicle Formed by Amphiphilc Cucurbit[6]uril: Versatile, Noncovalent Modification of the Vesicle Surface, and Multivalent Bindingof Sugar - Decorated Vesicles to leetin. J. Am. Chem. Soc. 2005, 127, 5006-5007.

18. Sindelar, V.; Cejas, M. A.; Raymo, F. M.; Kaifer, A. E. Tight inclusion complexation of 2,7-dimethyldiazapyrenium in cucurbit[7]uril. New J. Chem. 2005, 29, 280-282.

19. Freeman, W. A. Structures of the p-xylylenediammonium chloride and calcium hydrogensulfate adducts of the cavitand 'cucurbituril', $\mathrm{C}_{36} \mathrm{H}_{36} \mathrm{~N}_{24} \mathrm{O}_{12}$. Acta Cryst. 1984, B40, 382-387.

20. Heo, J.; Kim, S. Y; Whang, D; Kim, K. Shape-Induced, Hexagonal, Open Frameworks: Rubidum Ion Complexed Cucurbituril. Angew. Chem. Int. Ed. 1999, 38, 641-643. 
21. Sokolov, M. N.; Dybtsev, D. N.; Fedin, V. P. Supramolecular compounds of cucurbituril with molybdenum and tungsten chalcogenide cluster aqua complex. Russ. Chem. Bull. 2003, 52, 1041-1060.

22. Gerasko, O. A.; Sokolov, M. N.; Fedin, V. P. Mono and polynuclear aqua complexes and cucurbit[6]uril: versatile building blocks for supramolecular chemistry. Pure Appl. Chem. 2004, 76, 1633-1646.

23. Mu, L.; Xue S.-F.; Du, Y.; Zhao, Y.-J.; Zhu, Q.-J.; Tao, Z. Interaction Between Three Cucurbiturils and Hydrochloride Salts of 4,4'- Dipyridyl and Its Derivates. Chem. J. Chin. Univ. 2006, 27, 654-659.

24. Tao, Z.; Zhang, G.-Y.; Luo, X.-Q.; Xue, S.-F.; Zhu, Q.-J.; Jackson, W. G.; Wei, Z.-B.; Long, L.-S. $\mathrm{C}-\mathrm{H} \cdots \pi$ interactions in the $[\mathrm{Co}(N-(2$-aminomethylpyridyl)ethylenediamine $)(2$-aminomethylpyridine $) \mathrm{Cl}]^{2+}$ system: syntheses, 2D NMR, X-ray structures and energy minimizations ${ }^{* 1}$. Inorg. Chim. Acta. 2004, 357, 953-964.

25. Lin, R.-G.; Tao, Z.; Xue, S.-F.; Zhu, Q.-J.; Jackson, W. G.; Wei, Z.-B.; Long, L.-S. C-H... interaction in the $[\mathrm{Co}(\mathrm{N} \text {-(2-pyridylmethyl)-1,3-diaminopropane)(2-aminomethylpyridine }) \mathrm{Cl}]^{2+}$ system : syntheses, 2D NMR spectroscopy, X-ray structures and energy minimisations. Polyhedron 2003, 22, 3467-3474.

26. Tao, Z.; Zhu, Q.-J.; Jackson, W. G.; Zhou, Z.-Y.; Zhou, X.-G.; On the preference for the sym-fac isomer in the $\left[\mathrm{Co}\left(\mathrm{N}, \mathrm{N}^{\prime} \text {-bis(2-aminomethyl)amine }\right)\left(2,2^{\prime} \text {-bipyridine }\right) \mathrm{Cl}\right]^{2+}$ system. Polyhedron 2003, 22, 263-270.

27. Sheldrick, G. M. SHELXL-97 Program for the Solution and Refinement of Crystal structures; University of Göttingen: Göttingen, Germany, 1997.

Sample Availability: Contact the authors.

(C) 2008 by the authors; licensee Molecular Diversity Preservation International, Basel, Switzerland. This article is an open-access article distributed under the terms and conditions of the Creative Commons Attribution license (http://creativecommons.org/licenses/by/3.0/). 